\title{
Evaluation Of The Role Of Indocyanine Green Fluoroscopy For Intraoperative Bile Duct Visualization And Prevention Of Cbd Injury During Laparoscopic Cholecystectomy
}

\author{
Ahmed Muhammed Abdelaziz Muhammed ${ }^{1, *}$ M.B.B.CH, Hisham Wifky Anwar ${ }^{1}$ MD, \\ Tarek Zaghloul Muhammed ${ }^{1}$ MD
}

*Corresponding Author:

Ahmed Muhammed Abdelaziz Muhammed zizo49998@gmail.com

Received for publication October 13, 2021; Accepted January 14, 2022, Published online January 14, 2022.

Copyright The Authors published by Al-Azhar University, Faculty of Medicine, Cairo, Egypt. Users have the right to read, download, copy, distribute, print, search, or link to the full texts of articles under the following conditions: Creative Commons Attribution-Share Alike 4.0 International Public License (CC $B Y-S A$ 4.0).

doi:10.21608/aimj.2022.100939.1606

${ }^{I}$ General Surgery Department, Faculty of Medicine, Al-Azhar University Cairo, Egypt.

Disclosure: The authors have no financial interest to declare in relation to the content of this article. The Article Processing Charge was paid for by the authors. Authorship: All authors have a substantial contribution to the article.
ABSTRACT
Background: The most feared consequence of laparoscopic cholecystectomy is bile duct injury. Real-time intraoperative image with indocyanine green (ICG) may lower the danger of bile duct injuries during laparoscopic cholecystectomy by enhancing visualization of the biliary tree. The results of laparoscopic cholecystectomy in individuals with and without real-time ICG were compared and evaluated.

Aim of the work: The purpose of this prospective research is to assess the role of ICG in bile duct visualization and prevention of CBD injury throughout laparoscopic cholecystectomy, with preoperative injection of Indocyanine green ICG as regards outcome, prevention of intraoperative bile duct injury, technical difficulties, and postsurgical complications after converting from laparoscopic to open cholecystectomy.

Patients and methods: This prospective randomized study was carried out from March 2021 to September 2021 at the Department of General Surgery, Al-Azhar University Hospitals, Cairo , Egypt. It included 50 adult patients with chronic calcular cholecystitis. Those patients were classified into two equal groups: laparoscopic cholecystectomy (LC) with and without ICG was done. Comparison was applied between the two groups.

Results: During the study period, fifty patients who underwent laparoscopic cholecystectomy, 25 of whom had ICG and the other 25 did not. In the groups with and without ICG, the median duration of residence was 1.0 day, while the median length of operation was 43.0 minutes versus 86.0 minutes. In the group without ICG, conversion occurred at a rate of $2.4 \%$, whereas no conversion occurred in the ICG group. There was no bile duct injury in either group. There were no statistically significant differences between the groups.

Conclusion: Laparoscopic cholecystectomy with real-time indocyanine green fluorescence cholangiography improves vision and detection of the biliary tree and, as a result, ought to be regarded as a way to increase laparoscopic cholecystectomy safety.

Keywords: Laparoscopic cholecystectomy; Indocyanine green; Intraoperative fluorescence angiography; Bile duct injury.

\section{INTRODUCTION}

In the vast majority of instances (more than $80 \%$ ), they are asymptomatic. Gallstones are expected to be $17 \%$ prevalent at the time of mortality in the United Kingdom, and this number is likely to rise. Each year, about $1-2 \%$ of asymptomatic individuals may acquire symptoms necessitating an operation, rendering cholecystectomy one of the most frequent surgeries conducted by general surgeons. ${ }^{1}$

Complications of gallstone patients may include obstructive jaundice, acute cholangitis, acute pancreatitis, gallstone ileus, mucocele of gallbladder, empyema of gallbladder, biliary peritonitis and gallbladder cancer. ${ }^{2}$

The gold standard for the therapy of symptomatic gallstones, as well as other benign gallbladder diseases, is laparoscopic cholecystectomy (LC). It is one of the most commonly done procedures in the world, with over 750000 treatments conducted in the United States annually. Because of its quick acceptance by unskilled surgeons, there were some initial concerns regarding its safety. However, when a careful, correct technique is employed, the operation is extremely safe. ${ }^{3}$

Many strategies, such as intraoperative cholangiography (IOC), laparoscopic ultrasonography (LUS), cholecystocholangiography, and the critical perspective of safety, have been used to reduce the occurrence of bile duct injury (BDI) over the years. ${ }^{4}$

It is still debatable whether ICG should be used routinely in all cases of LC. While some researchers support routine ICG, others favour selective ICG in preventing biliary injuries. ${ }^{5}$ 
Intraoperative use of ICG in the course of LC during LC is beneficial not only in outlining the anatomy of the bile ducts and facilitating dissection, but also in preventing biliary tract injuries and diagnosing additional anomalies like fistulas, cysts, and biliary system tumors. ${ }^{6}$

During LC, Indocyaninegreen (ICG) must be used to avoid the most dangerous complications of laparoscopic cholecystectomy (common duct injury). Surgeons should train themselves to use intra-operative ICG to the point of perfection, so as to be able to utilize the technique if and when needed. ${ }^{5}$

\section{PATIENTS AND METHODS}

This randomized prospective trial was carried out from March 2021 to September 2021 at the Department of General Surgery, Al-Azhar University Hospitals, Egypt. It included 50 adult patients with chronic calcular cholecystitis. All patients were given a full assessment that included a detailed medical history, a thorough physical exam, laboratory tests, and an imaging study Ultra Sound (US) was performed to all patients.

All patients had pre-operative ultrasound commenting on the gall bladder wall thickness, the number of the stones, and their size along with other intra-abdominal and pelvic organs pathology. Patients to be excluded were those with suspected common bile duct stone or CBD dilatation, current jaundice or cholangitis, unfit patients.

Patients were classified into two equal groups: Group in whom LC was done after injection of ICG (Group 1), and Group in whom LC was done without ICG (Group 2). LC was done in all patients by the same surgical team using the standard technique of operation. The operative time was calculated from the start of the incision until placement of the last suture. The outcome and complications of $\mathrm{LC}$, the conversion rate to an open operation, the surgical time, and the length of stay in the hospital were all recorded. Hospital stay included all periods of admission for LC and recurrent biliary symptoms. All patients were followed up and instructed to notify the surgeon if there were any biliary symptoms.

Cost and availability: it was difficult to calculate the full cost due to different economic situation and the different in currencies and prices over the period of work on the research.

Also, the research material itself is available in the medical labor market in various regions and different medical companies

\section{STATISTICAL METHODS}

SPSS version 15 was used to analyze the data gathered (SPSS Inc., Chicago, IL, USA). The qualitative data was represented as numbers and percentages $(\%)$, whereas the quantitative data was represented as mean $\pm \mathrm{SD}$. The significance of the difference for quantitative data was tested using the independent student test, whereas the significance of the difference for qualitative data was tested using the Chi square or Fisher's exact test. A pvalue of $<0.05$ was deemed statistically significant.

\section{RESULTS}

There were no statistically significant differences (p-value > 0.05) among the groups studied in terms of laboratory Investigations and U/S findings (Table 1).

\begin{tabular}{|c|c|c|c|c|c|c|c|c|c|}
\hline & \multicolumn{4}{|c|}{ ICG } & \multicolumn{4}{|c|}{$\mathrm{LC}$} & \multirow{2}{*}{$\begin{array}{c}\mathrm{P} \\
\text { value }\end{array}$} \\
\hline & Mean & SD & Minimum & Maximum & Mean & SD & Minimum & Maximum & \\
\hline ALT & 30.35 & 9.14 & 11.00 & 43.00 & 29.80 & 9.75 & 12.00 & 45.00 & 0.855 \\
\hline AST & 23.65 & 9.06 & 9.00 & 37.00 & 24.15 & 7.21 & 13.00 & 38.00 & 0.848 \\
\hline Bil D & 0.21 & 0.06 & 0.13 & 0.33 & 0.20 & 0.06 & 0.10 & 0.30 & 0.682 \\
\hline ALP & 66.20 & 14.83 & 47.00 & 105.00 & 60.95 & 14.74 & 44.00 & 90.00 & 0.269 \\
\hline
\end{tabular}

Table 1: Comparison between the two groups as regarding Preoperative Biochemical data:

There were no statistically significant differences ( $\mathrm{p}$-value > 0.05) among the groups studied in terms of intraoperative and postoperative complications (Table 2). 


\begin{tabular}{|c|c|c|c|c|c|}
\hline & \multicolumn{2}{|c|}{ ICG } & \multicolumn{2}{|c|}{$\mathrm{LC}$} & \multirow{2}{*}{$\begin{array}{c}\mathrm{P} \\
\text { value }\end{array}$} \\
\hline & Count & $\%$ & Count & $\%$ & \\
\hline Intra-abdominal collection & 0 & $0.0 \%$ & 0 & $0.0 \%$ & ----- \\
\hline Wound infection & 0 & $0.0 \%$ & 1 & $4.0 \%$ & 1 \\
\hline Pancreatitis & 0 & $0.0 \%$ & 0 & $0.0 \%$ & ----- \\
\hline Bleeding & 0 & $0.0 \%$ & 0 & $0.0 \%$ & -.-- \\
\hline Bile duct injury & 0 & $0.0 \%$ & 0 & $0.0 \%$ & ----- \\
\hline Death & $\mathbf{0}$ & $0.0 \%$ & $\mathbf{0}$ & $0.0 \%$ & ----- \\
\hline
\end{tabular}

Table 2: Comparison between studied groups as regard postoperative complications.

\begin{tabular}{|c|c|c|c|c|c|}
\hline & \multicolumn{2}{|c|}{ ICG } & \multicolumn{2}{|c|}{$\mathrm{LC}$} & \multirow{2}{*}{$\begin{array}{c}\mathrm{P} \\
\text { value }\end{array}$} \\
\hline & Count & $\%$ & Count & $\%$ & \\
\hline Abdominal pain (1st two months) & 0 & $0.0 \%$ & 1 & $4.0 \%$ & 1 \\
\hline Jaundice (1st two months) & 0 & $0.0 \%$ & 1 & $4.0 \%$ & 1 \\
\hline Pancreatitis (1st two months) & 0 & $0.0 \%$ & 0 & $0.0 \%$ & $-\cdots$ \\
\hline Cholangitis (1st two months) & 0 & $0.0 \%$ & 1 & $4.0 \%$ & 1 \\
\hline Abnormal LFTs (1st two months) & 0 & $0.0 \%$ & 1 & $4.0 \%$ & 1 \\
\hline Readmission (1st two months) & 0 & $0.0 \%$ & 1 & $4.0 \%$ & 1 \\
\hline Abdominal pain (3rd mon) & 0 & $0.0 \%$ & 0 & $0.0 \%$ & ---- \\
\hline Jaundice (3rd mon) & 0 & $0.0 \%$ & 0 & $0.0 \%$ & --.- \\
\hline Pancreatitis (3rd mon) & 0 & $0.0 \%$ & 0 & $0.0 \%$ & ---- \\
\hline Cholangitis (3rd mon) & 0 & $0.0 \%$ & 0 & $0.0 \%$ & $-\cdots$ \\
\hline Abnormal LFTs (3rd mon) & 0 & $0.0 \%$ & 0 & $0.0 \%$ & ---- \\
\hline Readmission (3rd mon) & 1 & $4.0 \%$ & 0 & $0.0 \%$ & 1 \\
\hline Abdominal pain (6th mons) & 0 & $0.0 \%$ & 0 & $0.0 \%$ & ---- \\
\hline Jaundice (6th mons) & 0 & $0.0 \%$ & 0 & $0.0 \%$ & ---- \\
\hline Pancreatitis (6th mons) & 0 & $0.0 \%$ & 0 & $0.0 \%$ & ---- \\
\hline Cholangitis (6th mons) & 0 & $0.0 \%$ & 0 & $0.0 \%$ & --.- \\
\hline Abnormal LFTs (6th mons) & 0 & $0.0 \%$ & 0 & $0.0 \%$ & ---- \\
\hline Readmission (6th mons) & 0 & $0.0 \%$ & $\mathbf{0}$ & $0.0 \%$ & $-\cdots-$ \\
\hline
\end{tabular}

Table 3: Late postoperative complication and follow up data in both groups

\begin{tabular}{|c|c|c|c|}
\hline \multirow{5}{*}{ ICG (CBD) } & & \multicolumn{2}{|c|}{ ICG } \\
\hline & & Count & $\%$ \\
\hline & Normal & 42 & $84.0 \%$ \\
\hline & Dilated & 5 & $10.0 \%$ \\
\hline & Failed (narrow cystic) & 3 & $2.0 \%$ \\
\hline \multirow[t]{2}{*}{ ICG (biliary tree) } & Normal & 45 & $90.0 \%$ \\
\hline & Failed & 0 & $0.0 \%$ \\
\hline \multirow[t]{2}{*}{ biliary anatomy } & Normal & 24 & $96.0 \%$ \\
\hline & Failed & 1 & $4.0 \%$ \\
\hline \multirow[t]{2}{*}{ Visualization $\quad$ (Intrahepaticbile ducts) } & Yes & 24 & $96.0 \%$ \\
\hline & Failed & 1 & $4.0 \%$ \\
\hline \multirow[t]{2}{*}{ Visualization (extrarahepaticbile ducts) } & Yes & 24 & $96.0 \%$ \\
\hline & Failed & 1 & $4.0 \%$ \\
\hline Interventions done during LC & No & 25 & $100 \%$ \\
\hline \multirow[t]{2}{*}{ Allergy } & Yes & 0 & $0.0 \%$ \\
\hline & No & 25 & $100 \%$ \\
\hline Urine color change & No & 25 & $100 \%$ \\
\hline Stool color change & No & 25 & $100 \%$ \\
\hline Conversion to Open & No & 25 & $100.0 \%$ \\
\hline \multirow[t]{2}{*}{ Conservative management } & Yes & 0 & $0.0 \%$ \\
\hline & No & 25 & $100 \%$ \\
\hline
\end{tabular}

Table 4: Intra operative finding in group I 


\section{DISCUSSION}

The laparoscopic cholecystectomy (LC) procedure is one of the most prevalent in the world, with over 750 000 procedures done each year in the United States. Bile duct injury (BDI) is among the most feared complications of $\mathrm{LC}$, with a rate ranging from $0.4 \%$ to $1 \%$. It has an effect on long-term life quality and death rates, as well as puts a financial strain on healthcare systems. ${ }^{8}$

Many strategies, such as intraoperative cholangiography (IOC), laparoscopic U/S, cholecysto-cholangiography, and the safety critical view, were used to reduce the incidence of complications over the year. $^{9}$

The effectiveness of any of these procedures, however, is dependent on the correct evaluation of normal biliary anatomy, anatomical changes, and abnormal discoveries. ${ }^{10}$

The goal of this study is to evaluate the role of ICG versus laparoscopic cholecystectomy, through introducing statistics about how much ICG is effective, accurate, feasible, and safe in delineating the biliary tree, in detecting anatomical and pathological anomalies like filling deficiencies, fistulas, cysts, and biliary system tumors, and in detecting the role of ICG in decreasing morbidity and mortality rates.

The present study has been carried out as a controlled randomized study and conducted in the elective surgery theatres of the department of general surgery at El-Hussien \&Sayed Galal hospitals including 50 patients of mean age of $(39.73 \pm 10.69)$ years and dominance of female gender. These demographic features revealed statistically significant differences across the two groups. The study population consisted of 50 patients who were allocated into two groups at random; the first one submitted to laparoscopic cholecystectomy with ICG, and the 2nd group submitted to laparoscopic cholecystectomy only.

Shabanzadeh agree with us that is no significant gender-related difference in prediction of biliary stones. ${ }^{10}$

Tan JT stated that the advancing age as a predictor valuable but suggest male gender as a predictor instead. ${ }^{11}$

Arulampalam augments the old age theory too, many studies validates that the older the age the greater likelihood there is positive GB stones. ${ }^{12}$

Regarding morbidities of the selected patients, $17.5 \%$ of the patients were hypertensive. $12.5 \%$ of them were diabetic, and $0 \%$ of them had IHD.

Patients of the study had done laparoscopic cholycystectomy for chronic calcular cholycystitis (92.5\%), 0\% had acute calcular cholycystitis, also $7.5 \%$ had chronic calcular cholecystitis with history of jundice.

Regarding type of surgery all patients had been performed in elective basis. Visualization ability it is evident that one of the drawbacks of LC is the poor visualization, which might lead to bile duct injury. However, ICG compensates for this limitation by providing best rate of visualization. ${ }^{9}$

In our study, ICG successfully identified the structures of the biliary tree in 24 patients in group II. This agrees with previous studies with varying degrees, where ICG visualization rate of the cystic duct ranged between 71.4 to $100 \%$, and that of the common hepatic duct was $33.3-100 \%$, the CBD was $50-100 \%$, and the junction of the cystic duct and the common hepatic duct was $25-100 \%$. $^{8}$

These variations in the visualization ability of ICG are attributed to many factors. For example, the patient position, the contrast material itself and the surgeons experience. Improper position aside from supine position might affect visualization. Different quantity and quality of contrast materials also play a great role in visualization.

Expert surgeons are aware of the possible factors that hinder visualization such as air trapping and inadequate filling and adequate contrast materials. ${ }^{9-7}$

The high visualization ability of ICG is considered an advantage that counterweighs ICG invasiveness. Moreover, it surpasses other modalities such as ultrasound which cannot detect all biliary structures. ${ }^{7}$

Laparoscopic ultrasound can sometimes achieve $100 \%$ visualization rate, however, it has some limitations that made it underused. Firstly, it is highly dependent on the operators ${ }^{\text {ee }}$ experience. ${ }^{6}$ Secondly, it is associated with a learning curve for initial using.$^{6}$ thirdly, it is inefficient in differentiation of anatomical variations of the bile duct. Last but not least, it cannot determine the flow of bile into the duodenum. ${ }^{7}$

We proved that ICG is accurate in detection of biliary stones with high sensitivity and specificity $(100 \%)$. Previous studies augment this finding with similar high statistics. Ayloo $\mathrm{S}$ found that the sensitivity of ICG for detection of CBD stones is $97 \%$ and specificity is $99 \%{ }^{1}$

It's worthy to mention that all cases with ICG had a better visualization, feasibility and safety than other modalities such as ERCP and MRCP ${ }^{7}$

With the usage of ICG there was zero conversion to open cholecystectomy, less liability to other complications and better postoperative outcome.

\section{CONCLUSION}

paroscopic cholecystectomy with real-time indocyanine green fluorescence cholangiography improves vision and detection of the biliary tree and, as a result, ought to be regarded as a way to increase laparoscopic cholecystectomy safety.

\section{REFERENCES}

1- Alemi F, Seiser N, Ayloo S : Gallstone Disease: Cholecystitis, Mirizzi Syndrome, Bouveret Syndrome, Gallstone Ileus. Surgical Clinics.2019; 99(2): 231-44. 
2- Arora D, Kaushik R, Kaur R, Sachdev A : Postcholecystectomy syndrome: A new look at an old problem. Journal of minimal access surgery.2018; 14(3):, 202

3- Champault A, Vons C, Dagher I, Amerlinck S, Franco D : Low cost laparoscopic cholecystectomy. British Journal of Surgery.2020; 89: 1602-7.

4- Gupta A, Agarwal PN, Kant R, Malik V : Evaluation of fundus first laparoscopic cholecystectomy. Journal of the Society of Laparoscopic Surgeons.2020; 8: 255-8

5- Gurusamy KS \& Davidson BR : Gallstones. BMJ.2019; 348: 2669.

6- Hakuta R, Hamada T, Nakai Y, Oyama H, Kanai S, Suzuki T, Takahara N : association of endoscopic treatment with clinical outcomes. Journal of gastroenterology.2020; 55(1),78-85.

7- Lammert F, Gurusamy K, Ko CW, Miquel JF, Mendez- Sanchez N, Portincasa P, Wang DQH : Gallstones. Nature reviews Disease primers.2016; 2(1)-1-17.
8- Portincasa P, Di Ciaula A, De Bari O, Garruti G, Palmieri VO, Wang DH : Management of gallstones and its related complications. Expert review of gastroenterology \& hepatology.2016; 10(1): 93-112.

9- Schlumpf R, Klotz HP, Wehrli H, Herzog U : A nation's experience in laparoscopic cholecystectomy. Prospective multicenter analysis of 3722 cases. Surgical Endoscopy.2019; 8: 35-41

10-Shabanzadeh DM : Incidence of gallstone disease and complications. Current opinion in gastroenterology.2018; 34(2): 81-9.

11-Tan JT, Suyapto DR, Neo EL, Leong PS : Prospective audit of laparoscopic cholecystectomy experience at a secondary referral centre in South Australia. ANZ Journal of Surgery.2019 76: 335-8.

12- Taylor OM, Sedman PC, Jones BM, Royston CM, Arulampalam T, Wellwood J : Laparoscopic cholecystectomy with ICG: 238 cases over a 5general hospitals. Annals of Royal College of Surgery of England.2020; 79: 376-80. 